\title{
5. Apuntes para una filosofía de la educación en clave deleuziana. Un proyecto que se rizomatiza
}

\author{
Myriam García Rodríguez ${ }^{1}$ \\ DOI: https://doi.org/10.38017/9789588966458.05
}

\subsection{Introducción}

Este trabajo tiene como propósito mostrar que la enseñanza de la filosofía puede convertirse en una forma de resistencia, en una línea de fuga para generar procesos de creatividad, crítica y cuidado -tanto de sí mismo como del otro- en los jóvenes estudiantes. Para ello, se parte de la concepción de filosofía que emana de Gilles Deleuze, entendida como creadora de conceptos, así como de la concepción de enseñanza desde la que se cimienta el programa de Filosofía para Niños (FpN) elaborado inicialmente por Lipman y sus colaboradores, pero problematizado y ampliado posteriormente por diversos autores, como Walter Kohan, Angélica Sátiro y José Barrientos. En primer lugar, se va a ofrecer una breve introducción al lugar que ocupa la enseñanza de la filosofía en el sistema educativo actual, para después recoger los aportes conceptuales de Gilles Deleuze y Félix Guattari, especialmente relacionados con su concepción rizomática de la realidad. Finalmente, se argumenta a favor de los muchos puntos en común que existen entre el programa de FpN y la filosofía rizomática de Deleuze y Guattari, con el fin de reivindicar no solo una enseñanza de la filosofía de corte deleuziano, sino una nueva filosofía de la educación que convierta

1 Doctora en Filosofía y Máster en Estudios Sociales de la Ciencia y la Tecnología por la Universidad de Oviedo. Docente Investigador en distintas instituciones nacionales e internacionales, como la Universidad de Oviedo, el Centro de Estudios sobre Ciencia, Desarrollo y Educación Superior (Centro REDES, Buenos Aires) y la Organización de Estados Iberoamericanos (OEI). Sus líneas principales de investigación son la filosofía de la ciencia, la cultura científica y la percepción social de la ciencia y la tecnología. Formadora en el Programa de Filosofía para Niños. Instituto de Educación Secundaria "Rey Pelayo". Grupo de investigación CTS (Universidad de Oviedo).garciamyriam09@gmail.com 
la práctica filosófica en una poderosa herramienta pedagógica para poner en cuestión los modelos y órdenes imperantes. Una filosofía de la educación que, si bien se despliega en un recorrido centrado en la enseñanza de la filosofía, aspira a ser un proyecto educativo y una renovación curricular.

\subsection{Enseñar filosofía hoy}

¿Qué significa enseñar filosofía hoy? Para responder a esta pregunta, es necesario plantearse, en primer lugar, cuáles son los condicionantes sociales, políticos y económicos en los que se ejerce hoy la profesión docente, para después abordar el lugar que ocupa la filosofía en el sistema educativo actual. Solo entonces estaremos en condiciones de emitir un juicio de valor acerca de la situación, buena o mala, que vive la enseñanza de la filosofía y, en último término, cuál debería ser su papel. En este desiderátum final, va a ser de vital importancia las concepciones de filosofía y de educación de las que se parte.

Pues bien, a estas alturas parece estar suficientemente claro que estamos adentrándonos en un modelo de sociedad realmente nuevo desde el punto de vista económico, político, social y cultural. Uno de los rasgos principales de la sociedad del siglo XXI, es la influencia que la lógica del capitalismo ejerce en diversos planos de la vida social, no solo de tipo económico y político, sino también de carácter ideológico, cultural y actitudinal.

De acuerdo con Deleuze (1995), la sociedad de hoy ya no es la sociedad disciplinaria de Foucault, que consta de hospitales, psiquiátricos, cárceles, cuarteles y fábricas. Sus habitantes ya no son sujetos de obediencia, sino sujetos de rendimiento, emprendedores de sí mismos, que se entregan a un proyecto de progreso y libertad. Sin embargo, gozan de tan poca libertad como el sujeto de obediencia. La diferencia es que ahora el proceso mediante el cual el capital se apropia de nuestras mentes, produciendo cierto tipo de subjetividades, es el control por modulación. Mientras que en las sociedades disciplinarias descritas por Foucault, el poder opera 
siguiendo técnicas disciplinarias similares -el esquema negativo de la prohibición-, las sociedades de control descritas por Deleuze operan por inmanencia: el modelo de sociedad ya no es la prisión ni la fábrica, sino la empresa, y "la empresa es un alma, es etérea" (1995, p. 280). Ya no funciona sobre la base del encierro, sino del control continuo a través de procesos que nunca tienen término, como la formación permanente, la comunicación continua o la flexibilidad laboral ${ }^{2}$.

En el terreno de los afectos, la lógica capitalista modula igualmente nuestras mentes, forzándonos a pensar las relaciones en términos de costes y beneficios. De ahí la falta de consistencia y duración de los vínculos afectivos que denuncia Bauman (2005). Es la época de la atomización de la sociedad y la erosión de lo social, cuyo modo de comunicación es el propio de las redes sociales, limitado a los Likes o al Retweet, algo que se mide por su inmediatez y su valor de uso y de consumo. Este nuevo homo economicus, que todo lo valora en términos de rendimiento y beneficio, constituye en definitiva un modelo de individuo que corresponde a una mutación del capitalismo como capitalismo de hiperproducción, hiperrendimiento e hiperconsumo.

Un reflejo de este modo de producción capitalista, basada en la lógica de la dominación y la instrumentalización de la razón, se ve en los discursos y en las prácticas que definen las últimas reformas educativas y ajustes curriculares. En esta línea, Martha Nussbaum (2010) denuncia una profunda crisis de las humanidades como consecuencia de la creciente mercantilización de la educación. Los espacios académicos dedicados a la filosofía y las humanidades ven reducidas sus horas en detrimento de materias más utilitaristas y orientadas al emprendimiento profesional que, bajo criterios economicistas, privilegian las destrezas técnicas y hábitos de

2 A este respecto, José Luis Pardo (2004) señala la flexibilidad como una práctica central del nuevo capitalismo. Específicamente, el empleo flexible: el período de formación permanente de un individuo se identifica con la longitud completa de su vida laboral, a lo largo de la cual debe estar dispuesto a reciclarse, reformarse redefinirse y reajustarse cuantas veces sea necesario y en la medida en que lo sea. 
comportamiento exigidos por las relaciones sociales de producción capitalista. El pensamiento se reduce a "pensamiento estratégico"3.

Quizá la causa de esta incipiente crisis filosófica resida en la tesis comúnmente aceptada de que la formación filosófica es demasiado abstracta e inútil para la vida cotidiana, y que los currículos plantean como objetivos prioritarios que los estudiantes conozcan los conceptos básicos, los principales enfoques y los autores representativos de la disciplina. Pero esto no siempre fue así. La filosofía no siempre consistió en el postulado de teorías abstractas ni en la exégesis de textos, sino en la formación integral del individuo, siguiendo la idea de paideia o socialización del buen ciudadano. Tal era la concepción de la filosofía defendida por los antiguos grecolatinos, entendida como el cultivo de un arte de vivir asociado a los problemas más inmediatos de la vida cotidiana. Una caja de herramientas para aprender a pensar, ser y vivir.

Hoy, su vigencia no ha disminuido. Si atendemos a las predicciones de cambios sociales, tecnológicos y científicos que se esperan para las próximas décadas y que van a tener gran impacto de transformación en las personas, la sociedad, los negocios y la administración, la importancia de la enseñanza de la filosofía es incuestionable. Las sociedades democráticas necesitan que sus ciudadanos sean capaces de pensar, de concebir soluciones y vías alternativas para las decisiones prácticas, respetarse a sí mismos y respetar a los demás, comprender la conducta ajena y ser capaz de ponerse en el caso de otras personas (Nussbaum, 2010). Esto implica que no podemos considerar la realidad como algo incuestionable, acabado y cerrado. Es preciso pensarla y presentarla como algo problemático, abierto, revisable y criticable, que invita a la discusión

3 Si bien esta crisis de las humanidades es una tendencia universal, sirva aquí como ejemplo el caso concreto de España. En la última reforma educativa, la Ley Orgánica para la Mejora de la Calidad Educativa (LOMCE) de 2013, ha desplazado el ejercicio del pensar a un pequeño reducto de materias cuyo peso en el currículum ha disminuido drásticamente no solo por el número de horas, sino también por los niveles en los que se imparten, así como por su condición de optatividad. 
y a la clarificación. Para esta tarea, la práctica de la filosofía, tanto por los temas que plantea como por el modo en que lo hace, se revela como un proceso que puede ser extremadamente efectivo para desarrollar en los estudiantes las herramientas precisas para desenvolverse en un contexto de cambios rápidos y globales.

Sin embargo, como ya se viene anunciando, el capitalismo procede de un modo inmanente, no tiene más límites que sí mismo y no cesa de sobrepasarlos, por lo que cae en la paradoja de demandar un individuo que ya no existe, porque lo ha roto. Es lo que Max Horkheimer (2002) denominó "el ocaso del individuo". El individuo de la modernidad, sujeto de pensamiento autónomo y de solidaridad social, es sustituido por el individuo tecnócrata, ingeniero o manager, y por el individuo-masa, neutralizado y manipulado por la industria cultural. Encapsulado en sus propios intereses privados, y reducido a simple productores-consumidores, el individuo atomizado es incapaz de dirimir asuntos públicos en aras del bien común y la justicia social. En la misma línea, son muchos los analistas que hoy llaman la atención sobre esta inquietante paradoja de la moderna racionalización: los imperativos del actual sistema de globalización capitalista están conduciendo a una evidente reducción y neutralización del individuo, concretamente del trabajador, al tiempo que la moderna industria cultural o cultura de masas atrofia la capacidad de resistencia de los individuos mediante el pensamiento "estereotipo", la homogeneización y la seducción ${ }^{4}$ (véase, al respecto, Bauman, 2001; Sánchez Noriega, 1997; o Sennet, 2001, entre otros).

Es necesario, por tanto, encontrar microfisuras, líneas de fuga que permitan subvertir los órdenes de pensamiento hegemónicos. La filosofía de Deleuze y Guattari, caracterizada por la denuncia del racionalismo y la reivindicación de la diferencia, la multiplicidad y la fragmentación, se convierte para los momentos actuales en una

4 Incluso la popularización de la filosofía a modo de cura anímica-Más Platón, menos prozac- cae en la lógica del sistema y la instrumentalización, convertida en mercancía de la industria cultural, orientada al ocio pasivo y la trivialidad. 
poderosa herramienta de interrogación y ruptura, que permite a las personas que entran en contacto con ella diseñar nuevas formas de resistencia.

\subsection{La práctica de la filosofía como línea de fuga}

Según Deleuze (1969), desde tiempos de Parménides, la filosofía occidental ha intentado interpretar el mundo usando las categorías de identidad y negación, imponiendo así una lógica que impide pensar la realidad como algo múltiple y diverso. Esta insistencia en la identidad explica el modo en que los filósofos han intentado unificar todo el conocimiento disponible con la aspiración de elaborar una ciencia global que incluya todos los saberes. La metáfora del árbol del conocimiento empleada por Descartes ilustra, de manera muy gráfica, la insistencia de la filosofía tradicional por lo unívoco, sólido y absoluto. Sin embargo, esta tendencia de la modernidad a la identidad, a la jerarquización y a la unificación, no es más que el resultado de un proceso de totalización que, de forma violenta, somete todo cuanto existe a la disciplina de la identidad racional, excluyendo la diferencia y renegando de la diversidad.

Deleuze confía en poder evitar los errores en los que han caído los filósofos anteriores, cegados por la búsqueda de una verdad única, absoluta y definitiva, y aspira a articular una forma de pensamiento que sea respetuosa con la diversidad, la interconexión y la multiplicidad de los sentidos. Se va a oponer abiertamente a toda la filosofía heredada -no solo de la modernidad sino de todo el platonismo- y a ubicarse claramente en una nueva forma de entender la filosofía, no como mera contemplación de la realidad, sino como creación o construcción de conceptos (Raffin, 2008). Así, en ¿Qué es la filosofía?, leemos:

(...) la filosofía, con mayor rigor, consiste en crear conceptos... crear conceptos siempre nuevos... El concepto remite al filósofo como aquel que lo tiene en potencia, o que tiene su poder o su competencia, porque tiene que ser creado... Los conceptos no están esperando hechos y acabados, como cuerpos celestes. No hay 
firmamento para los conceptos. Hay que inventarlos, fabricarlos o más bien crearlos, y nada serían sin la firma de quienes los crean (Deleuze y Guattari, 1993, p. 11).

La concepción de la filosofía cambia radicalmente. Entender la filosofía como una actividad que inventa, que crea conceptos, implica entenderla desde una dimensión práctica. No es una actividad pasiva, meramente teórica o reflexiva, sino que es acción. Por extensión, la función del filósofo consistirá en crear conceptos, inventarlos, y los conceptos se convertirán en una caja de herramientas válidas para la acción que se desea, y ello sin detrimento de que esos conceptos abran el camino a la multiplicidad y otras posibilidades de pensar, ser y vivir (Raffin, 2008).

En Mil Mesetas, Deleuze y Guattari amplían su tesis de que lo real está constituido por una multiplicidad irreductible de planos que ningún sujeto puede controlar. Es decir, una multiplicidad no tiene ni sujeto ni objeto, sino únicamente determinaciones, dimensiones heterogéneas que no pueden aumentar o decrecer sin que ella cambie de naturaleza: "una multiplicidad se define por el número de sus dimensiones; no se divide, no pierde o gana ninguna dimensión sin cambiar de naturaleza" (Deleuze y Guattari, 1980, p. 254). En la medida en que implica nuevas conexiones, la multiplicidad se transforma en otras multiplicidades: "el devenir y la multiplicidad son una sola y misma cosa" (p. 254). Sellega así al concepto de rizoma: "lo múltiple hay que hacerlo, pero no añadiendo constantemente una dimensión superior, sino, al contrario, de la forma más simple, a fuerza de sobriedad, al nivel de las dimensiones de que se dispone, siempre $\mathrm{n}-1 .$. Este tipo de sistema podría denominarse rizoma" (Deleuze y Guattari, 1980, p. 13).

Intentando imaginar formas distintas de pensar la realidad, Deleuze y Guattari proponen sustituir la imagen del árbol por la del rizoma, tomando como referencia los tallos subterráneos, como bulbos o tubérculos. "Un rizoma como tallo subterráneo se distingue radicalmente de las raíces y de las raicillas; se ramifica en todas las direcciones. Los bulbos, los tubérculos, son rizomas" (Deleuze y Guattari, 1980, p. 13). 
Mientras que el árbol parte de un eje principal que centra y articula toda la estructura, sigue un camino lineal y obedece a una lógica binaria que procede por dicotomías, los rizomas se caracterizan por tener una estructura reticular y compleja. Carecen de un centro o punto común que sirva de fundamento, y se extienden en una difusa y extensa red de interconexiones. En un rizoma un punto puede ser conectado con cualquier otro (Chirolla, 2005). Así se hace un rizoma, de muchas mesetas. "Nosotros llamamos 'meseta' a toda multiplicidad conectable con otras por tallos subterráneos superficiales, a fin de formar y extender un rizoma" (Deleuze y Guattari, 1980, p. 33). Los rizomas se disponen en mesetas. Ésa es su configuración geográfica, las mesetas lo constituyen. La meseta tiene una ubicación intermedia, no está ni al principio ni al final, siempre está en el medio, pudiendo desarrollarse en cualquier dirección formando nuevas mesetas (Raffin, 2008).

Pues bien, ese movimiento que lleva de una multiplicidad a otra, describe un proceso de desterritorialización y de reterritorialización. El primero, en el sentido en que una multiplicidad es arrastrada hacia un umbral en el que ya no conservara su naturaleza; y, el segundo, en que entra en una nueva, sus segmentos, estratos o dimensiones constituyen nuevas conexiones. Cuando se producen conexiones inesperadas, entre puntos fijos y segmentos bien delimitados, se producen microfisuras por donde huyen las multiplicidades. Entonces, obtenemos una línea de fuga o de desterritorialización absoluta (Chirolla, 2005).

Desde esta perspectiva, la filosofía deja de ser una sucesión de sistemas, para convertirse en una coexistencia de planos de orden conceptual (Pulido Cortés, 2011). Ya no consiste en asimilar o justificar, sino en sentir de otra manera. Implica otras sensibilidades, otras direcciones, otras formas de existencia que transgredan los órdenes de lo mismo y lo idéntico (Deleuze, 1986). En este sentido, la función del filósofo es la de adoptar el papel del extranjero, el único que puede señalar, al hacerlo desde fuera, esas contradicciones, convencionalismos absurdos o asunciones acríticas en las que estamos sumidos, siendo ciegos y sordos 
a la crítica y al cambio ${ }^{5}$. Así entendida, la filosofía no es solo un ejercicio creativo sino también crítico. La creación deviene crítica y la crítica deviene creación, puesto que solo a través del movimiento del pensamiento, de la resistencia y de las líneas de fuga, la filosofía se convierte en creación de nuevas posibilidades de vida (Pulido Cortés, 2011).

Enseñar a pensar de manera crítica y creativa se convierte, entonces, en la principal labor del filósofo. Es decir, la filosofía en su función crítica-creativa ha de ser entendida como el ejercicio libre por el cual el sujeto se atribuye el derecho de interrogar la realidad, comprendiendo que lo que ha sido construido como verdad es susceptible de ser criticado, lanzarse a la búsqueda de nuevos conceptos que le permitan comprender realidades cada vez más cambiantes y extrañas, e inventar nuevas maneras de acción y de resistencia que le permitan defenderse en su cotidianidad de los embates cada más fuertes de la sociedad de control.

Ahora bien, aprender a pensar crítica y creativamente depende, en gran medida, de la práctica, de ahí que sea necesario que los estudiantes tengan la oportunidad de familiarizarse con el gusto por la pregunta y la investigación, la argumentación, la sensibilidad ética y la creatividad en la resolución de problemas. Surge entonces la pregunta ¿Existe algún tipo de metodología didáctica que favorezca ese campo de experiencia donde se elaboran esas multiplicidades? ¿Existe algún tipo de práctica pedagógica que pueda hacer posible esa experiencia rizomática? Entendida desde la perspectiva deleuziana, enseñar filosofía no puede consistir en un procedimiento operativo de transmisión y repetición de contenidos, sino en el diálogo realizado en una comunidad que busca, trabaja e investiga conjuntamente. El programa de FpN elaborado inicialmente por Mathew Lipman y

5 De este modo, para que se haga efectiva la acción del filosofar, el sujeto debe ponerse en cuestión, atravesado por la experiencia de la pregunta, en la misma dirección que lo plantea Deleuze cuando sostiene que hay que poner todo en una bolsa a condición de que también coloque al profesor Deleuze en ella (Deleuze y Parnet, 1980). 
Ann Sharp es quizá uno de los más adecuados, ya que posibilita un aprendizaje significativo, estimulando la reflexión y ayudando al cuestionamiento y replanteamiento de todos aquellos temas y asuntos que pueden preocupar al alumnado. Uno de sus aspectos más novedosos reside en el uso de una metodología dialógica, que favorece la participación de los estudiantes en la construcción colectiva del conocimiento. El objetivo no es la asimilación y apoyo acrítico de todo lo transmitido por el docente, ni una crítica global infundada, sino facilitar que los estudiantes aprendan a expresar sus opiniones, a hablar y a escucharse, ayudándoles a encontrar y delinear el camino propio como un sujeto autónomo. Su propuesta de transformar el aula en una comunidad de investigación y sus aportaciones con respecto al origen social del pensamiento, permiten desarrollar un proyecto educativo basado en la mejora de las habilidades de pensamiento.

Recientemente, otros autores han elaborado nuevas aproximaciones y propuestas, cuyo foco de interés no se centra tanto en mejorar las herramientas del razonamiento lógico como en explorar el uso de otras racionalidades. Es el caso de la "filosofía con niños" de Walter Kohan (2006), el Proyecto Noria de Irene de Puig y Angélica Sátiro (2011) o "la experiencialidad" de José Barrientos (2016). Sus trabajos actualizan el Programa original de Lipman a partir del abordaje de otras formas de filosofía, como la razón vital de José Ortega y Gasset, la razón poética de María Zambrano o la razón ontológica-estética de Hans-Georg Gadamer. Lo que prima no es la reflexión conceptual, entendida como una actividad apartada de la vida misma, sino la conexión entre el pensar, el sentir y el actuar (véase también al respecto Helou et al., 2019).

En este contexto de renovación y nuevas aproximaciones, la propuesta de este trabajo es reivindicar no solo una enseñanza de la filosofía de corte deleuziano, sino una nueva filosofía de la educación que aúne los aportes conceptuales de Deleuze y Guattari, especialmente relacionados con su concepción de la filosofía, y las herramientas pedagógicas proporcionadas por el programa de FpN. Una filosofía de la educación que, si bien se despliega en un 
recorrido centrado en la enseñanza de la filosofía, aspira a ser un proyecto educativo y una renovación curricular.

\subsection{Filosofía para Niños. Un proyecto educativo que se rizomatiza}

Al entrar en contacto con la obra de Lipman y sus colaboradores, se perciben diversos rasgos en su propuesta que ponen de relieve un punto de contacto entre la práctica educativa de FpN y el pensamiento de Deleuze y Guattari. En concreto, es posible reconstruir el andamiaje de $\mathrm{FpN}$ a través de sus dimensiones rizomáticas.

\subsection{La filosofía como práctica}

Como ya se ha señalado, para Deleuze la filosofía es actividad. Así lo expresa en su obra Spinoza. Filosofía práctica. Contrariamente a lo que pudiera dejar pensar el título, a Deleuze no le interesa interpretar una vez más la filosofía de Spinoza, sino rastrear la definición de una práctica de la filosofía, una definición del acto mismo de filosofar y no solo de su enunciación. La filosofía deja de ser sustantivo para convertirse en verbo, una práctica e incluso un modo de vida. En esta misma línea, Foucault entiende la filosofía como

[...] una cierta manera de pensar, de decir, también de actuar, una cierta relación con lo que existe, con lo que sabemos, con lo que hacemos, una relación con la sociedad, con la cultura, también una relación con los otros, y que podríamos llamar, digamos, la actitud crítica (Foucault, 1995, p. 5).

Pudiera parecer, entonces, que existe un cierto alineamiento con el giro práctico que se produjo en la filosofía en la década de los años 60 y que se ha dado a conocer como "práctica filosófica", incluyendo modalidades tan diversas como el asesoramiento filosófico, los cafés filosóficos o los talleres de filosofía. A pesar de que estas prácticas filosóficas aparecen en momentos contextos diferentes y con características muy diversas entre sí, todas ellas comparten una concepción similar de la filosofía. El objetivo consiste no tanto 
en aprender una serie de conceptos o sistemas filosóficos, sino en filosofar. No se trata de aprender filosofía, sino de aprender a filosofar (Arnaiz, 2007). El proyecto educativo de FpN se incluye dentro de este movimiento, convencido de que la filosofía puede adquirir un papel fundamental en la educación desde los primeros años de la infancia. De este modo, FpN se opone a la relación tradicionalmente dicotómica entre filosofía e infancia, que nace con Platón y atraviesa la pedagogía cristiana de San Agustín hasta llegar al racionalismo cartesiano.

¿No es una excelente precaución prohibirles la dialéctica cuando son demasiado jóvenes? No ignoras, sin duda, que los jóvenes, cuando han recibido las primeras lecciones de la dialéctica, se sirven de ella como de un pasatiempo, y tienen fruición en provocar controversias sin cesar. A ejemplo de los que les han confundido en la disputa, ellos a su vez confunden a los demás, y semejantes a los perros jóvenes, se complacen en ladrar y despedazar con el razonamiento a cuantos se les aproximan... Después de muchas disputas en que han salido unas veces vencidos y otras, vencedores, concluyen, por lo ordinario, por no creer nada de lo que creían antes. De esta manera dan ocasión a que los demás los desacrediten a ellos y a la filosofía (Platón, República, Libro VII: 88).

Desde entonces, la tradición filosófica occidental ha interpretado la infancia como un "mal necesario, una condición próxima al estado animalesco y primitivo”. Descartes, por ejemplo, ve a los niños y jóvenes como seres privados de razón y elabora, al igual que Platón, una reforma de la educación para corregir sus tendencias salvajes y encaminarlos hacia la luz natural de la razón para volvernos adultos o, como decía Kant, salir de la "minoría de edad". En oposición a esta tradición, Nietzsche reivindica la figura del niño:

Pero decidme, hermanos míos ¿qué es capaz de hacer el niño que ni siquiera el león ha sido capaz de hacerlo?, ¿por qué el león rapaz tiene que convertirse todavía en niño? Inocencia es el niño, y olvido, un nuevo comienzo, un juego, una rueda que se mueve por sí misma, un primer momento, un santo decir sí. Sí, hermanos míos, para el juego del crear se precisa un santo decir sí: el espíritu quiere ahora su voluntad (Nietzsche, 1992). 
Ya no se trata de corregir la naturaleza infantil, sino de ayudar al desenvolvimiento de las facultades infantiles, más auténticas e inocentes que las convenciones sociales que las pervierte. La infancia aparece como un paraíso perdido. Esta idea de Nietzsche y su crítica a los valores de la cultura occidental, constituye una de las tantas razones que llevaron a Deleuze a oponerse abiertamente a toda la filosofía heredada -no solo de la modernidad, sino de todo el platonismo- y ubicarse claramente en una nueva forma de entender la filosofía, no como mera contemplación de la realidad, sino como creación o construcción de conceptos que nos hacen avanzar en la comprensión y la solución de los problemas. Los conceptos, dice Deleuze, se crean con la única "condición de que satisfagan una necesidad y de que presenten cierta extrañeza, cosa que solo sucede cuando responden a problemas verdaderos" (Deleuze, 1999, p. 217).

En la misma línea, Lipman basa todo su proyecto educativo en el anhelo de sentido de los niños. La filosofía, dice, "es sumamente beneficiosa para las personas que buscan formular conceptos que puedan representar con eficacia aspectos de su experiencia vital" (Lipman et al., 1992, p. 87). Ahora bien, Lipman aclara que los significados no se pueden dar o transmitir a los niños, sino que tienen que adquirirlos por sí mismos. ¿Y cómo podemos ayudar a que los niños consigan alcanzar el sentido por sí mismos? Pues, enseñándoles a pensar: "pensar es la capacidad por excelencia que nos capacita para lograr significados". De ahí que el objetivo del programa sea "enseñar a pensar mejor".

\subsection{Los actos mentales como sistemas multilineales}

Lipman concibe el pensamiento como una habilidad: "pensar es natural, pero también es posible considerarlo como una habilidad susceptible de perfeccionamiento. Hay formas más eficaces y menos eficaces de pensar. Podemos decir esto con confianza puesto que poseemos los criterios que nos permiten distinguir entre un 
pensamiento hábil y otro torpe" (Lipman et al., 1992, p. 68). Esto le llevó a hablar de cuatro especies de habilidades mentales ${ }^{6}$.

No obstante, es importante señalar que el propio Lipman advierte que pensar es algo complejo que desborda cualquier lista de habilidades. La clasificación que se propone tiene un objetivo meramente pedagógico, ya que permite realizar actividades concretas, orientadas a un objetivo claro. Por otro lado, si bien la clasificación que se ofrece ayuda a organizar y planificar, hay que tener en cuenta que las habilidades se trabajan siempre de manera simultánea, con relaciones y conexiones entre unas y otras, pero del que no somos conscientes. Pensemos, por ejemplo, en todo lo que hacemos durante el transcurso de un diálogo: identificar supuestos implícitos, sacar inferencias acerca de lo que el hablante intenta implicar, especular sobre diversas intenciones, desarrollar tus propias intenciones para responder al comentario, decidir el tipo de énfasis en el comentario (exclamación, pregunta, ironía), etc. (Lipman et al., 1992). Es decir, un enorme volumen de actos mentales con relaciones y conexiones multilineales. Los actos mentales son, pues, rizomáticos. Funcionan como sistemas multilineales, donde las líneas se entrecruzan pudiendo darse simultáneamente múltiples procesos. Ya Deleuze y Guattari,

6 Aquellas que implican el examen de un asunto problemático, desde la formulación de hipótesis hasta selección de evidencias, y desde el planteamiento de experimentos hasta la verificación de las predicciones (habilidades de investigación); aquellas que no tienen que ver con la adquisición de conocimientos, pero sí con la extensión y justificación del mismo (habilidades de razonamiento); aquellas que implican la organización de informaciones difusas en conjuntos manejables, una vez que hemos interiorizado los conocimientos y les ponemos nombre (habilidades de conceptualización); y, finalmente, aquellas que representan una manera importante de pensar, necesarias para explicitar, aplicar o formular el resultado del conocimiento (habilidades de traducción). En un trabajo posterior, Irene de Puig y Angélica Sátiro agregan un quinto grupo de habilidades de percepción o perceptivas: "las habilidades de percepción recogen impresiones y sensaciones de la realidad que, conectadas con nuestras capacidades interiores, generan percepciones del mundo. Algunas habilidades de percepción son escuchar atentamente, oler, saborear, tocar, percibir movimientos y conectar sensaciones” (Puig y Sátiro, 2011, p. 29). 
siguiendo al neurobiólogo Steven Rose, habían reconocido al pensamiento como un rizoma: "el pensamiento no es arborescente, el cerebro no es una materia enraizada ni ramificada" (Deleuze y Guattari, 1980, p. 24).

Ahora bien, ¿cómo podemos mejorar nuestras habilidades de pensamiento? En el proyecto educativo de FpN, el diálogo filosófico es el método elegido para ejercitar las distintas competencias y actitudes filosóficas; y la comunidad de investigación es el medio propuesto para llevarlo a cabo.

\subsection{El diálogo filosófico como interconexión}

Frente a la asunción tradicional de que el pensamiento es algo interior y privado, Lipman establece una relación bidireccional entre diálogo y pensamiento: la reflexión genera el diálogo, y el diálogo genera la reflexión. De este modo, pensamiento y lenguaje aparecen como dos caras de una misma moneda: "el acto de pensar está tan estrechamente relacionado con el lenguaje que podemos sospechar con fundamento que aprender a hablar, a pensar y a razonar son actividades estrechamente ligadas entre ellas" (Lipman et al., 1992, p. 73).

Los niños van adquiriendo un pensamiento cada vez más complejo y rico a medida que se apropian del lenguaje. De ahí la importancia del diálogo. En ese diálogo, necesariamente tendremos que aprender a argumentar de manera adecuada, estructurada y cuidadosa, lo que activa la maquinaria de nuestro pensamiento de forma inmejorable. Es decir, mejoramos de manera constante nuestro lenguaje para ser adecuadamente entendidos por el otro, lo que hace que nuestro pensamiento se estructure mejor. Además, el diálogo con los otros permite lo que Lipman llama la "interiorización del diálogo": en el diálogo no solo respondemos en nuestro interior a las opiniones de los demás, sino que reproducimos los pensamientos que acabamos de escuchar. Aprendemos a pensar mejor viendo cómo piensan los demás. Aprendemos a pensar mejor con el otro. Ideas que ya están presentes en la psicología cognitiva y social de George Herbert 
Mead y de Lev Vygotsky. Vygotsky, por ejemplo, afirma que existe una diferencia entre la manera de resolver los problemas de manera individual y la manera de resolverlos con otros, y esa diferencia es cualitativa; es una diferencia en el nivel de ejecución: resolvemos mejor los problemas cuando los resolvemos con otros (Lipman et al., 1992).

La idea que descansa en esta acción colaborativa es una de las más significativas para entender la imbricación entre FpN y Deleuze: desde ambas perspectivas, se reconoce a cada uno de los miembros de la comunidad como sujetos integrales, con un pasado, presente y futuro, de los que es posible aprender. En este sentido, el diálogo es rizomorfo. De la misma manera que el rizoma se diferencia de las raíces que tienen los árboles, porque en estas últimas suele haber un eje principal que centra y articula toda la estructura, en el diálogo socrático no hay un centro ni tampoco un lugar o un punto privilegiado. Lo característico del diálogo, al igual que del rizoma, es la interconexión, que le permite expandirse y sobrevivir sin necesidad de un núcleo claramente definido o de un elemento predominante.

La finalidad del diálogo no es la mera conversación, ni el discurso persuasivo, ni la derrota del oponente, sino el cuestionamiento o la problematización de un tema o situación que nos interpela de un modo u otro. Para esta tarea, se insiste en una determinada manera de entender la práctica en el aula, la práctica de convertirla en una comunidad de reflexión formada por individuos comprometidos con la exploración de temas complejos. Se llega entonces a "la comunidad de investigación".

\subsection{La comunidad de investigación como espacio rizomorfo}

El objetivo de la comunidad de investigación es conseguir que cada alumno interiorice el proceso de investigación y adquiera autonomía en el pensar. Por un lado, fomentar la investigación significa conseguir que los estudiantes se sientan estimulados a buscar, examinar con atención, cuestionar, inquirir. Por otro lado, 
la idea de comunidad implica la creación de un clima afectivo, de confianza mutua, donde los estudiantes puedan hablar y ser escuchados con respeto y dondela única regla de oro sea la corrección con respecto al tono de las intervenciones, evitando agresividades y violencias verbales, así como el rigor en las exposiciones y en la argumentación. El reto pedagógico consiste en ayudar a que cada persona se implique a sí misma en sus devenires sujetos, mediante creaciones, críticas, cuidado de sí y de los otros. Se recupera así una perspectiva ética abierta por Foucault, entendida como una relación entre uno con uno mismo y con los otros seres, siempre en vinculación con los saberes que nos rodean y nos constituyen subjetivamente y que, simultáneamente, constituimos (Foucault, 2006).

El método de trabajo no es tanto la transmisión de conocimiento preciso e inequívoco mediante la absorción de datos e información provenientes del docente, sino el aprendizaje por descubrimiento basado en la resolución de problemas en un ambiente de indagación donde los alumnos puedan manejar información relevante, intercambiar opiniones, articular conocimientos y formular argumentos y contra-argumentos. Ideas que ya están presentes en el constructivismo social de Bruner y Vygostky. En lugar de concebir la mente como un recipiente pasivo y vacío que debe ser rellenado con información y contenidos meramente teóricos, se presupone que el alumnado aprende al estar involucrado de manera activa a través de la interacción con el ambiente y resolviendo problemas relacionados con su realidad próxima. En esa exploración conjunta, se sustituye la competitividad por el esfuerzo conjunto. El diálogo, el respeto mutuo y el razonamiento de las propias opiniones son prácticas que terminan convirtiéndose en el modo normal de conducta de los estudiantes y el docente.

Ahora bien, para que esta comunidad de investigación se constituya realmente, todos, docente y alumnos, deben involucrarse en la búsqueda, vistos como co-investigadores. El diálogo no debe mantenerse entre el docente y sus alumnos, puesto que en este caso nos encontraríamos más bien ante una clase magistral en la que 
el docente siempre tiene la última palabra. De ahí que el docente deba renunciar al rol tradicional de "experto", visto como fuente de información y autoridad. Se recuperan así las enseñanzas socráticas. El docente no se presenta a sí mismo como un sabio, sino como un ignorante que pide ser instruido por sus alumnos y busca iniciar una investigación en comunidad. El diálogo asume así la tarea hermenéutica de interpretar la realidad, con el fin de darle sentido. Para ello, sigue la estructura lógica de la pregunta/respuesta ${ }^{7}$. De ahí que no haya que subestimar la función del docente, puesto que su papel es crucial y delicado. Asume la función de mediador mayéutico, ayudando a estimular el intercambio de opiniones, ideas y puntos de vista.

De este modo, el docente se convierte en un filósofo-topo que construye madrigueras -un espacio rizomático- excavando túneles que ramifican en todas las direcciones. La comunidad de investigación es, pues, rizomorfa, abierta a la construcción y deconstrucción del conocimiento.

"Ser rizomorfo es producir tallos y filamentos que parecen raíces, o, todavía mejor, que se conectan con ellas al penetrar en el tronco, sin perjuicio de hacer que sirvan para nuevos usos extraños. Estamos cansados del árbol. No debemos seguir creyendo en los árboles, en las raíces o en las raicillas, nos han hecho sufrir demasiado. Toda la cultura arborescente está basada en ellos, desde la biología hasta la lingüística. No hay nada más bello, más amoroso, más político que los tallos subterráneos y las raíces aéreas, la adventicia y el rizoma" (Deleuze y Guattari, 1980, pp. 23-24).

7 De acuerdo con Gadamer, quien pregunta reconoce explícitamente que no sabe. La pregunta es así, una vacuna contra el dogmatismo. El dogmatismo no necesita preguntar, pues cree saber todo cuanto hay que saber. Además, quien pregunta acepta el riesgo de ser sorprendido por la respuesta. En este sentido, la pregunta filosófica es diferente de otros tipos de preguntas que suelen tener lugar en la escuela, preguntas para saber qué sabe el alumno, preguntas para averiguar la solución. La pregunta manifiesta así la condición íntima de la experiencia humana, pues toda experiencia es una búsqueda. 
Así, con la imaginería de las arborescencias, Deleuze y Guattari cristalizan su profunda crítica a la noción de autoridad heredadas de toda la filosofía occidental. Tal es la propuesta de FpN, siguiendo los planteamientos de Paulo Freire y su pedagogía de la autonomía. Frente al modelo educativo que denomina "educación bancaria" (Freire, 1970, p. 78), Freire propone un método dialógico horizontal, en el cual el estudiante se reconoce a sí mismo y aprende del educador, pero el educador también aprende del estudiante y reconoce su propia humanidad. Ambos se hacen a la vez "educadores y educandos". De esta manera, el educador ya no es solo aquel que educa, sino también aquel que es educado por el educando en el proceso de educación, a través del diálogo que se sostiene. Y los educandos ya no son receptores pasivos, sino investigadores activos y críticos que comprenden el mundo que les rodea no ya como una realidad estática y separada, sino como una realidad en cambio y transformación mutua.

Se trata, en definitiva, de seguir la ruta trazada por Dewey y su insistencia en una educación democrática, entendiendo la democracia no en sentido formal o institucional, sino como forma de vida y de organización individual y social. El proceso educativo ya no consiste en decirle al sujeto que aprende lo que debe o no debe hacer, sino en hacerle partícipe y artífice de su propia vida, tomando conciencia de la realidad que le rodea y comprometiéndose de forma crítica con su transformación.

He aquí el sentido de la práctica filosófica: exaltar una pedagogía del vivir que saca a la luz las preguntas para poner en cuestión la realidad que nos rodea, a nosotros mismos, a los otros y nuestra relación con ellos. Llevada al aula, la práctica filosófica permite introducir en el sistema educativo un permanente procedimiento de cuestionamiento y deconstrucción de los supuestos que cimentan nuestro presente social, político y cultural (Kohan y Waksman, 2005).

En este punto cabe señalar, de acuerdo con los planteamientos del aprendizaje significativo, que los estudiantes se sentirán mucho 
más dispuestos a participar en un diálogo en el que se puedan plantear problemas parecidos a los suyos, temas que les interesen o les interpelan de algún modo. Algo que tradicionalmente se ha hecho partiendo de un relato, un cuento, una fábula. De ahí que Lipman y sus colaboradores propongan el uso de novelas con protagonistas que viven situaciones con las que los estudiantes se puedan identificar. Ello implica conocer los saberes previos de los/ as estudiantes, sus intereses e inquietudes, a fin de conseguir que se impliquen en el aula y se apropien de los contenidos que allí se tratan para su uso en la vida diaria.

\subsection{El "texto" como multiplicidad}

Al igual que ocurriera con el diálogo, lectura y pensamiento son interdependientes. Por un lado, hay que tener en cuenta que leer no es solo pronunciar las palabras y oraciones que aparecen en un texto, sino también, y sobre todo, encontrar las conexiones, identificar qué está sugiriendo esa oración. Cuando leemos un texto, activamos nuestros procesos de pensamiento. Por otro lado, hay que tener en cuenta que la lectura no es un fin en sí mismo, sino un medio, un medio para elaborar conceptos y conseguir significados. Uno lee para conseguir significados. Por eso, los niños que no consiguen descubrir el significado de lo que leen, abandonan la lectura (Lipman et al., 1992).

"Estamos hartos de los libros con raíces en rectas (en cualquiera de sus versiones, pivotante -objeto- o dicotómica -sujeto-) o fasciculadas (o sistema raicilla). Los árboles de este tipo son asfixiantes" (Deleuze y Guattari, 1980, p. 13).

Con estas palabras, Deleuze y Guattari están describiendo, sin pretenderlo, el sistema educativo actual, fácilmente comparable con los sistemas arborescentes. El aula funciona como un sistema jerárquico donde solo se recibe información de una unidad superior, el libro de texto. Los estudiantes se enfrentan a una gran cantidad de información, pero administrada de forma desconectada a su experiencia, a su vida. El resultado, dice Lipman, es la realidad 
que vemos casi todos los días: niños aburridos y apáticos, cuya curiosidad ha sido destruida, y cuya percepción de la escuela comienza a parecerse cada vez más a la de un recinto, una especie de "guardería" o "aparcamiento infantil", en el que está obligado a quedarse (Lipman et al., 1992, pp. 65-66).

La responsabilidad de la escuela es proporcionar o disponer las condiciones y oportunidades necesarias para que los niños den ellos mismos- significado a las cosas; para que consigan alcanzar el sentido por sí mismos. ¿Y cómo podemos ayudar a que los niños consigan alcanzar el sentido por sí mismos? A través de una narrativa filosófica que estimule la formulación de preguntas típicamente humanas, acerca de la felicidad, la vida, la muerte, la amistad, el amor, etc. Preguntas que no necesariamente tiene una respuesta cerrada, acotada o definitiva, pero cuyo valor no reside en las respuestas que proporcionan, sino en la búsqueda de significado que representan. Esto implica también tener una concepción amplia de lo que se entiende por "texto". Como dice Maximiliano López, "texto es todo aquello que se nos presenta como un signo... Estrictamente hablando, todo el mundo y cada una de sus partes pueden ser considerados un signo, dado que signo es todo aquello que consideramos como teniendo algo para decir, como teniendo un sentido (López, 2008, p. 98).

Desde ese punto de vista, los "textos" que pueden ser utilizados en el aula son innumerables: novelas, cuentos, cuadros, películas, poemas, canciones, objetos o situaciones. Todo puede despertar el pensamiento.

Así entendido, un "texto" no tiene objeto ni sujeto, es una multiplicidad deleuziana. FpN aparece, entonces, como una práctica compleja que consiste en considerar el "texto" como un rizoma que habilita a posibilidades nunca clausuradas de lecturas y preguntas; y "leer" como un movimiento rizomático que abre puntos de fuga de importancia fundamental para solventar las deficiencias de los currículos tradicionales, inmóviles y carentes de significación. 


\subsection{Hacia un currículum escolar de forma reticular}

Una de las características más importantes del rizoma quizá sea la de tener siempre múltiples entradas, como la madriguera, que es un rizoma animal (Raffin, 2008). Mientras que el árbol simboliza la unidad y la totalidad, el rizoma es la imagen de la multiplicidad y la diversidad. Un rizoma no responde a ningún modelo estructural o generativo. Es ajeno a toda idea de eje genético, como también de estructura profunda. "El rizoma, así, carece de centro" (Deleuze y Guattari, 1980, p. 30).

Frente a las clases especializadas, donde cada materia son cajones estancos desconectados unos de otros -lengua, matemáticas, naturales, sociales-, el interés de la filosofía transciende las disciplinas y las atraviesa transversalmente. Así, por ejemplo, la filosofía puede plantearse preguntas acerca de ¿qué es el colonialismo?, ¿qué es la gravedad?, ¿qué es la división?, ¿cuál es la diferencia entre poesía y prosa?, ¿cuáles son los criterios para escribir bien?, etcétera.

De ahí que, Lipman proponga la integración del programa en todos los aspectos del currículum. Esto supone tratar los contenidos como rizomas, donde la organización de los elementos no sigue líneas de subordinación jerárquica con una raíz, dando origen a múltiples ramas, sino un modelo rizomático en el que cualquier elemento puede afectar o incidir en cualquier otro sin importar su posición recíproca. Un rizoma puede ser roto, alterado, iniciado e interrumpido en cualquier punto, pero siempre reconecta con cualquier otro (Raffin, 2008). Ni estáticos, ni partimentados, ni jerarquizados, los currículos educativos se imbrican en un movimiento reticular a través de las habilidades de pensamiento planteadas por Lipman y sus colaboradores. De este modo, la filosofía proporciona unidad y continuidad a la experiencia educativa. 


\subsection{Algunas consideraciones finales}

El contexto actual convierte la enseñanza en un problema filosófico. La lógica del capitalismo, basada en la producción y la urgencia consumista, modula todos los aspectos de nuestra vida, nuestra forma de pensar, actuar y relacionarnos. El profesorado, apremiado por la urgencia de cumplir la programación, solicita métodos, técnicas y recursos para aplicar eficientemente en el aula con el único objetivo de transmitir la mayor cantidad posible de contenidos. Por su parte, el alumnado se enfrenta a una enorme cantidad de información desconectada de su propia experiencia y pospone, ante la ansiedad de dar una respuesta correcta, toda reflexión o indagación sobre uno mismo. No queda espacio, en el sistema educativo actual, para la pregunta o el cuestionamiento en torno al sentido de colocar un recurso en la clase, sus motivaciones, sus posibles efectos, etcétera (Agratti, 2011).

Hacer frente a esta situación conlleva pensar la enseñanza como un problema filosófico, de modo que sea posible ensayar una filosofía de la educación que cuestione e indague conceptos tan consolidados como "profesor", "alumno", "aula", "texto", "leer" o "evaluación”. Todos estos conceptos han sido interpelados constantemente desde la propuesta de FpN. Su propuesta de transformar el aula en una comunidad de investigación que favorece la participación de los estudiantes en la construcción colectiva del conocimiento y el uso de una metodología dialógica que estimula la reflexión y el cuestionamiento de los saberes previos, la convierten en una de las más adecuadas para llevar a cabo una filosofía de la educación en clave deleuziana. Esto es, una práctica pedagógica que pueda hacer posible ese campo de experiencia rizomorfa donde se elaboran multiplicidades.

Esta nueva pedagogía tiene, además, importantes consecuencias políticas, ya que la auténtica democracia solo puede desarrollarse cuando aceptamos que en la realidad conviven visiones parciales, diversas, múltiples y enfrentadas entre sí. Si verdaderamente creyéramos que existe una verdad única y definitiva, la democracia no tendría sentido, porque lo sensato sería entregar el gobierno 
a quien conoce la auténtica realidad. Este es justamente el sueño totalitario, pero la democracia no se basa en la verdad, sino en la interpretación, el pacto y la elaboración en común de significados compartidos. En palabras de Vattimo, "el adiós a la verdad es el inicio, y la base misma, de la democracia" (2010, p. 18).

Desde esta perspectiva, enseñar no puede consistir en un procedimiento operativo de transmisión y repetición de contenidos presentados como "verdades últimas", sino un ejercicio mayéutico de "dar a luz" aquellos conceptos que nos permitan comprender $\mathrm{y}$ funcionar en un mundo que nos provoca extrañeza. Enseñar es promover la crítica y el cuestionamiento que lleva a la investigación y la creatividad. En este sentido, el docente-facilitador de preguntas, revelador de conceptos, necesita ser lo suficientemente flexible para llevar a cabo su tarea, privilegiando los intereses y preguntas de sus estudiantes por encima de las urgencias curriculares, acompañándoles en la búsqueda de respuestas y la construcción colectiva del conocimiento, trazando puentes y encontrando conexiones como si de un cartógrafo se tratara. Ello implica sin duda un modo de entender la enseñanza, una manera de trabajar y una disposición y preparación del profesorado. De ahí que, para Lipman, el futuro de la filosofía en el aula dependa de la formación del profesorado, no solo para comprender la dimensión filosófica de las diversas áreas académicas, sino también para aprender cómo alimentar y agudizar las preguntas típicamente filosóficas de los estudiantes.

Ahora bien, resulta conveniente señalar que esta pretensión convierte la práctica de $\mathrm{FpN}$ en una paradoja. En el mismo momento en que se enseña y transmite en aulas reglamentadas siguiendo un programa específico, FpN se institucionaliza y, al hacerlo, suprime aquello que es propio a la filosofía; a saber, el cuestionamiento, la indagación y la deliberación (Agratti, 2011). En esta misma línea, Jacques Derrida (1986) ya había señalado una serie de demandas contradictorias de la institución filosófica y de las que derivan un conjunto de problemas propios de la enseñanza de la filosofía. Derrida fija el número de antinomias en siete, aunque aquí solo se 
van a recuperar tres. Así, por ejemplo, Derrida señala la paradoja de enseñar lo inenseñable (tercera antinomia); la contradicción de institucionalizar la filosofía (cuarta antinomia); y, la antinomia temporal de la enseñanza de la filosofía (sexta antinomia).

En relación con la tercera antinomia, Derrida sostiene que la filosofía ha reivindicado a través de toda su historia ser enseñada, puesto que no resiste no ser enseñada y, sin embargo, no puede, en su gesto principal, ser enseñada. En la cuarta antinomia, Derrida señala a contradicción de exigir la creación de nuevas instituciones filosóficas al tiempo que se reconoce que la filosofía no puede ser institucionalizada, debido a que su propósito sobrepasa toda institución. La filosofía es una disciplina imposible y necesaria a la vez. Por último, la sexta antinomia hace referencia a la propia experiencia del pensar filosófico, cuyo ritmo y duración particular, más lento y prolongado, se encuentra con la temporalidad propia de la escuela, sujeta a calendarios, horarios, exámenes, etc.

La pregunta que cabe hacerse, entonces, es $\dot{i}$ son compatibles estas antinomias con la práctica de FpN?, ¿es posible llevar la filosofía al aula? En su análisis de las antinomias de Derrida, Walter Kohan (2008) toma una de las consecuencias que se extraen de las mismas para afirmar, junto con Derrida, que una comunidad filosófica que merezca ese nombre es aquella que no niega esas antinomias, sino que hace de sus condiciones paradójicas una oportunidad para pensarse a sí misma e investigar lo que puede surgir a partir de ellas. De este modo, lejos de paralizar, esta situación paradojal muestra toda la potencia y relevancia de llevar la filosofía al aula, ya que retrata un elemento esencial de toda actitud filosófica; a saber, aquella que abre nuevos interrogantes sobre aquellos conceptos aparentemente asentados ${ }^{8}$.

8 Incluso Deleuze y Guattari llegaron a reconocer en Mil mesetas que siempre es posible que sobre un rizoma crezcan estructuras arborescentes, que algunas multiplicidades se sedimenten, de tal modo que controlen, al menos en parte, el devenir, se reterritorialicen alrededor de un centro de irradiación, a partir del cual se establece una jerarquía. Pero, también reconocieron que es posible que, en medio de una estructura arborescente, empiecen a proliferar rizomas (Chirolla, 2005). 
Las revisiones del programa original de Lipman y sus colaboradores, con nuevas aproximaciones y propuestas como la "filosofía con niños" de Walter Kohan (2006), el Proyecto Noria de Irene de Puig y Angélica Sátiro (2011) o "la experiencialidad" de José Barrientos (2016); dibujan un espacio rizomático que aparece como resistencia a estructuras arborescentes al señalar, entre otros aspectos, que pensar no es solo un conjunto de habilidades cognitivas, de estrategias para resolver problemas, sino también una aventura, una experiencia vital. Lejos de convertirse en un credo, sus tensiones son fuente de inspiración crítica, porque nos permite seguir pensando y explorando nuevas ideas.

Así, la filosofía de Deleuze, encarnada en la filosofía de la educación de Lipman y aquellas que vinieron después como filosofía para/ con/desde la infancia, han perpetrado un verdadero acto de subversión en el pensamiento filosófico contemporáneo. Su signo es la práctica filosófica, entendida como una actividad crítica y creativa que aparece como forma de resistencia y línea de fuga a la creciente mecanización del pensar. Hoy, favorecer un espacio para "pararse a pensar", es casi un acto revolucionario; y hacerlo desde la multiplicidad, una necesidad.

\section{Referencias}

Agratti, L. (2011). El encuentro de la filosofía con la infancia en la experiencia de enseñar a enseñar filosofía como cuestión de fundamento. Childhood \& Philosophy, 7(14), 221-232.

Arnaiz, G. (2007). El giro práctico de la filosofía. Diálogo filosófico, $68,170-206$.

Barrientos, J. (2016). La experiencialidad como respuesta a la tendencia analítica de la filosofía para niños. Childhood \& Phylosophy, 12(25), 519-542.

Bauman, Z. (2001). La sociedad individualizada. Cátedra.

Bauman, Z. (2005). Amor líquido: acerca de la fragilidad de los vínculos humanos. Fondo de Cultura Económica. 
Chirolla, G. A. (2005). Capitalismo y filosofía. Una aproximación desde Deleuze. Universitas Philosophica, 44- 45, 175-186.

Deleuze, G. (1995). Sobre la filosofía. En Conversaciones (pp. 215246). Pre-textos.

Deleuze, G. (1999 [1995]). Postscriptum sobre las sociedades de control. En Conversaciones (pp. 277-281). Pre-textos.

Deleuze, G. (2004 [1986]). Nietzsche y la filosofía. Anagrama.

Deleuze, G. (2002 [1969]). Diferencia y repetición. Amorrortu editores.

Deleuze, G., y Guattari, F. (1993). ¿Qué es la filosofía? Anagrama.

Deleuze, G., y Guattari, F. (2004 [1980]). Rizoma. En Mil Mesetas. Capitalismo y esquizofrenia (pp. 9-30). Pre-textos.

Deleuze, G., y Guattari, F. (1980). Mil Mesetas. Capitalismo y esquizofrenia. Pretextos.

Deleuze, G., y Parnet, C. (1980). Diálogos. Pre-textos.

Derrida, J. (1986). Les antinomies de la discipline philosophique. La Grève des philosophes: école et philosophie (pp. 9-31). Osiris.

Foucault, M. (2006). La hermenéutica del sujeto. Fondo de Cultura Económica.

Foucault, M. (1995). ¿Qué es la crítica? Daimon Revista de Filosofía, 11, 5-25.

Freire, P. (1970). Pedagogía del oprimido. Siglo XXI Editores.

Helou, L., Magallanes, R., Monzón, C., y Russo, J. (2019). Método arqueológico educativo. HASER Revista Internacional de Filosofía Aplicada, 10, 37-64.

Horkheimer, M. (2002). Crítica de la razón instrumental. Trotta. 
Kohan, W. (2008). Filosofía, la paradoja de aprender y enseñar. Zorzal.

Kohan, W. (2006). Teoría y práctica en filosofía con niños y jóvenes: experimentar el pensar, pensar la experiencia. Novedades educativas.

Kohan, W., y Waksman, V. (2005). Filosofía con niños. Aportes para el trabajo en clase. Novedades educativas.

Lipman, M., Sharp, A. M., y Oscanyan, F. (1992). La filosofía en el aula. Ediciones de La Torre.

López, M. (2008). Filosofía con niños y jóvenes. La comunidad de indagación a partir de los conceptos de acontecimiento y experiencia trágica. Novedades educativas.

Lyotard, J. F. (2006 [1979]). La condición postmoderna. Cátedra.

Nietzsche, F. (1992). Así habló Zaratustra (trad. A. Sánchez Pascual). Alianza editorial.

Nussbaum, M. (2010). Sin fines de lucro. Por qué la democracia necesita de las humanidades. Katz.

Pardo, J. L. (2004). Las reglas del juego Sobre la dificultad de aprender filosofía. Galaxia Gutenberg.

Platón. (1872). Obras completas. Tomo 8 (Ed. Azcárate, P). Medina y Navarro editores.

Pulido Cortés, O. (2011). Aprender y enseñar filosofía en el mundo contemporáneo: De la mercantilización del pensamiento al despliegue de su ejercicio. Cuestiones de Filosofía, 11. https:// doi.org/10.19053/01235095.653

Raffin, M. (2008). El pensamiento de Gilles Deleuze y Michel Foucault en cuestión. Lecciones y Ensayos, 85, 17-44. 
Sánchez Noriega, J. L. (1997). Crítica de la seducción mediática. Comunicación y cultura de masas en la era de la opulencia informativa. Técnos.

Sennet, R. (2001). La corrosión del carácter: las consecuencias personales del trabajo en el nuevo capitalismo. Anagrama.

Vattimo, G. (2010). Adiós a la verdad. Gedisa. 